ANNA DALOS (Budapest)

\title{
Háry auf der Reise nach Wien. Die Uraufführung von Kodálys Theater-Ouvertüre in der Gesellschaft der Musikfreunde in Wien
}

Der Titel meiner Studie* beruft sich bewußt auf Eduard Mörikes Novelle „Mozart auf der Reise nach Prag“. Die Handlung der Novelle, die auf halbem Weg zwischen Wien und Prag spielt und in der der Komponist und seine Frau einige angenehme Stunden bei einer böhmischen Adelsfamilie verbringen, ist eine Fiktion. Zoltán Kodálys Held, János Háry, macht eine ähnlich fiktive Reise nach Wien, wo er die Hochachtung des Kaisers gewinnt und wo sich sogar die KaiserTochter Marie Luise in ihn verliebt. Die zeitgenössischen Kritiker des Singspiels waren sich darin einig, daß Háry ein Doppelgänger Kodálys ist. ${ }^{1}$ Trotzdem veranlaßt mich dieser Umstand nicht dazu, zu behaupten, daß die Uraufführung der Theater-Ouvertüre am 29. März 1932 (Abbildung) auch als eine Fiktion angesehen werden kann. In meiner Studie versuche ich hingegen, einerseits die Fragen der Umstände der Uraufführung zu beantworten und andererseits klarzulegen, warum die Rezeption dieses Werkes sowohl in Wien als auch weltweit auf Hindernisse stieß und warum die Ouvertüre nicht Teil des Kodály-Kanons wurde.

Zoltán Kodály nahm an der Uraufführung im großen Musikvereinssaal nicht teil. Die Konzert-Version der Ouvertüre wurde zum ersten Mal von den Wiener Symphonikern unter der Leitung von Robert Heger aufgeführt, weil Kodály mit der Ouvertüre, die ursprünglich für das Singspiel „Háry János“ geschrieben wurde, zum Zeitpunkt von dessen Premiere (am 16. Oktober 1926) nicht fertig geworden war; als Vorspiel wurde sie dann gemeinsam mit drei anderen Nummern erst am 10. Jänner 1928 im Budapester Königlichen Opernhaus uraufgeführt. ${ }^{2}$ Außerdem erklang die Ouvertüre auch bei der „Háry“-Aufführung des

* Ich möchte meinen Dank an Frau Sarolta Kodály aussprechen, die ermöglichte, daß ich die Dokumente der Theater-Ouvertüre im Budapester Kodály-Archiv einsehe. Die Vorbereitung dieser Studie wurde von dem "Lendület"-Programm der Ungarischen Akademie der Wissenschaften gefördert.

1 Bence Szabolcsi, Háry János, in: Ferenc Bonis (Hg.), Kodályról és Bartókról. Szabolcsi Bence müvei 5 [Über Kodály und Bartók. Schriften von Bence Szabolcsi 5], Budapest 1987, S. 64-70; Sándor [Alexander] Jemnitz, Rendkívüli Filharmóniai hangverseny - Kodály és Honegger zsoltára [Sonderkonzert der Philharmonie - die Psalmen Kodálys und Honeggers], in: Vera Lampert (Hg.), Jemnitz Sándor válogatott zenekritikái [Ausgewählte Musikkritiken von Sándor Jemnitz], Budapest 1973, S. 142-145, hier S. 142. Die Kritik erschien am 5. Februar 1928.

2 Siehe den Bericht von Bence Szabolcsi aus dem Jahre 1928: A Háry János új számai [Die neuesten Nummern von Háry János], in: Bonis (Hg.), Kodályról és Bartókról (Anm. 1), S. 83-85. 
Gefellidaft der Mulikfreube in Wien

Gpiel3eit $1931 / 82$

120. Bereingjahs

Grojer Mulfituereins = Gaal

Dienstag, den 29. Tär子 1932, abends $1 / 28 \mathfrak{u h r}$

\section{Adthtes (leftes)}

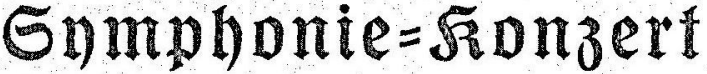

3 hI $1931 \cdot 1932$

Dirigent: fiomsertbireffor

\section{Brofeffor Robert Seger}

Mitwitkend:

\section{Bablo Cajals}

A ustubrenbe:

Das Wiener Gymphonie=Drchejfer

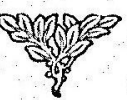

Program 30 Brolden

Program $\mathrm{m}$ :

3olfán STodály:

(Geb. 16. Dezember 1882, febt it Fuadueft)

Gingipiel=Duterture

(Urauffủsung)

Uraufführung der „Singspiel=Ouverture“ von Zoltán Kodály am 29. März 1932. Abendprogramm, Ausschnitte (Archiv der Gesellschaft der Musikfreunde in Wien) 
Stadttheaters von Köln am 26. September 1931, wurde allerdings - wie aus den Kritiken zu erfahren ist - wesentlich gekürzt. ${ }^{3}$

Die Ouvertüre schließt mit dem Volkslied „Sej, Nagyabonyban“, das später, am Ende des Singspiels, als Apotheose funktioniert. Kodály schrieb aber für die Konzert-Uraufführung ein neues Ende, das thematisch mit der Ouvertüre in Verbindung steht und gleichzeitig - nach Weglassen des Volksliedes - als eindeutiger Abschluß dient. Diese Version - die Kodály nach Daten des Haushaltungsbuches seiner Frau Emma am 4. Dezember 1931 beendete ${ }^{4}$ - wurde 1932 bei Universal-Edition veröffentlicht. ${ }^{5}$ Aus einem Brief Kodálys an den Verlag, datiert mit dem 29. Februar 1932, wissen wir, daß er das druckfertige Manuskript Anfang Dezember 1931 an den Verlag schickte; die Redaktion reagierte aber auf diese Sendung nicht. ${ }^{6}$ Trotzdem baten sie Kodály in einem Brief vom 21. März um Erlaubnis, die Partitur an einigen Stellen verkürzen zu dürfen. ${ }^{7}$ Die ungarischen Kodály-Forscher waren unsicher, ob die Wiener Uraufführung überhaupt stattfand, ${ }^{8}$ da Kodály diesen Brief erst am 25. April, also fast einen Monat nach dem Zeitpunkt des Konzertes, beantwortete. Immerhin gab er seine Einwilligung, die Partitur zu kürzen:

Bezügl.[ich] der Háry-Ouvertüre macht mir erst die zufällige Ankunft Prof.[essor] Hegers hier die Antwort auf Ihre w.[erten] Zeilen vom 21sten möglich. Ich entnehme seinen Worten dass er nur eine ad. lib.[itum]-Kürzung die mit vi $==$ de angezeigt werden soll, vorschlägt. Da willige ich natürl.[ich] ohne weiteres ein, und das hat ja auf die Herstellungsarbeiten keinen weiteren Einfluss. ${ }^{9}$

Der Brief macht deutlich, daß es Robert Heger war, der den Komponisten über den Vorschlag des Verlages informierte. Die zwei Musiker konnten die Sache persönlich besprochen haben, als Heger an der Budapester Musikakademie am 23. April 1932 Händels „Messias“ dirigierte. ${ }^{10}$ Die scheinbar verspätete Antwort

3 János Breuer, Kodály-kalauz [Kodály-Handbuch], Budapest 1982, S. 152.

4 Referenznummer im Kodály-Archiv: H.N. 0931.240.

5 Zoltán Kodály, Theater-Ouvertüre, Wien 1932.

6 Dezső Legánÿ / Dénes Legánÿ (Hg.), Zoltán Kodály Letters in English, French, German, Italian, Latin, Budapest (Argumentum-Kodály Archívum) 2002, S. 191.

7 Ebenda, S. 194.

8 János Breuer (Anm. 3) sah das Konzert als unsicher an (S. 153), da László Eösze das Konzert gar nicht erwähnt: Kodály Zoltán életének krónikája [Die Chronik des Lebens von Zoltán Kodály], Budapest 1977.

9 Legán̈̈/Legánÿ (Anm. 6), S. 194.

10 Siehe dazu die Datenbank „Konzertkatalog der Konzerte in Budapest“: http://b.zti.hu/koncert/koncert_Kereses.asp (Archiv für ungarische Musik des 20. und 21. Jahrhunderts, Institut für Musikwissenschaft, Zentrum für Geisteswissenschaften, Ungarische Akademie der Wissenschaften). 
Kodálys macht klar, daß der Kürzungsvorschlag nicht nur die stattgefundene Aufführung betraf: Möglicherweise brachten gerade Hegers Erfahrungen mit dem Werk den Verlag dazu, den Vorschlag mit der ad-libitum-Kürzung der Ouvertüre zu machen. Die erste Ausgabe von 1932 sowie die zweite Ausgabe aus dem Jahre $1952^{11}$ bewahren jedoch keine Spuren dieses Vorschlags. Wie János Breuer bewies, neigte Kodály selbst dazu, seine Werke nach den ersten Hörerfahrungen, manchmal sogar nach der Uraufführung, zu modifizieren. ${ }^{12} \mathrm{Er}$ dürfte aber die neue Version der Theater-Ouvertüre erst am 11. Dezember 1932 in Budapest gehört haben. ${ }^{13}$

Der Verlag bat durch Vermittlung Hegers den Komponisten auch darum, seinem Werk einen neuen Titel zu geben. Der Vorschlag „Singspiel-Ouvertüre" gefiel selbst dem Dirigenten nicht, da man dadurch - wie Kodály formulierte - „etwas Bestimmtes erwartet, was sich mit dem Inhalt des vorl.[iegenden] Werkes nicht deckt. ${ }^{\text {" }}{ }^{14}$ Schließlich entschied sich Kodály für den Titel „Theater-Ouvertüre", da er, wie er meinte, ein ,internationales Wort“ ist. Das Werk wurde im großen Musikvereinsaal noch mit dem Titel „Ouvertüre zum János Háry" uraufgeführt. ${ }^{15}$ Robert Heger machte sich auch Sorgen, daß das Publikum meinen könnte, die Ouvertüre sei zur „Háry-János-Suite " geschrieben worden. ${ }^{16}$ Vermutlich hatte der durchschnittliche Konzertbesucher keine Kenntnis davon, daß die populäre Suite von 1927 aus einem Singspiel zusammengestellt wurde. Zweifelsohne gehörte die Suite neben den 1929 orchestrierten „Marosszéker Tänzen“ zu den weltweit bekanntesten Werken Kodálys. Nach Angaben in der Zeitschrift „Anbruch“ wurden die „Marosszéker Tänze“ 1932 in den Großstädten der Welt zehnmal gespielt, die „Háry-Suite“ sechsmal. ${ }^{17}$ Selbst die Wiener Symphoniker, die die Uraufführung der Theater-Ouvertüre absolvierten, spielten die „Marosszéker Tänze" zweimal in jenem Jahr: zum ersten Mal unter der Leitung von Hermann Abendroth, zum zweiten Mal von Herbert Winkler dirigiert. ${ }^{18}$

11 Zoltán Kodály, Theater-Ouvertüre, Wien (Universal-Edition) 1952.

12 János Breuer, Kodály korrekciói kiadott mủveiben [Kodálys Korrekturen in seinen veröffentlichten Werken], in: ders., Kodály és kora [Kodály und seine Zeit], Kecskemét (Kodály Intézet) 2002, S. 30-45.

13 Siehe dazu die Datenbank (Anm. 10).

14 Legánÿ / Legánÿ (Anm. 6), S. 194.

15 Siehe die Datenbank der Wiener Symphoniker: http://www.wienersymphoniker.at/archiv/konzert/ pid/000000e9h58h00011d50.

16 Legánÿ / Legánÿ (Anm. 6), S. 194.

17 Anbruch. Monatsschrift für moderne Musik XIV. Jg., Heft IX/X (Dezember 1932), S. 222.

18 Datenbank der Wiener Symphoniker (Anm. 15). 
Die Aufführung und die Propagierung der Theater-Ouvertüre als selbständiges Werk soll jedoch auch andere Hintergründe gehabt haben. Kodály feierte 1932 seinen 50. Geburtstag. Die Universal-Edition, mit der Kodály zwölf Jahre früher durch Béla Bartóks Vermittlung einen Vertrag eingegangen war, ${ }^{19}$ setzte sich vor dem Ereignis für die Popularisierung von Kodálys Werken und Persönlichkeit ein. Kodálys Jugendfreund, der Musiktheoretiker und Pianist Rudolf Réti, würdigte ihn im „Anbruch“. ${ }^{20}$ Es scheint, daß die Universal-Edition die internationale Reputation Kodálys beträchtlich fördern wollte, was dadurch ermöglicht wurde, daß dem Verlag genug repräsentative Orchesterwerke von Kodály zur Verfügung standen.

Als Kodály am 26. August 1920 den Vertrag mit der Universal-Edition unterzeichnete, einigten sich die beiden Parteien darin, daß zehn Kompositionen veröffentlicht werden, die der Ernte der ersten Schaffensperiode Kodálys entsprechen und alle Kammer- und Klavierwerke sowie Lieder auf Gedichte von ungarischen Dichtern umfassen. ${ }^{21}$ Das heißt, der Verlag konnte im Hinblick auf Kodálys Euvre nur mit einem relativ beschränkten Markt rechnen. Der große Erfolg des 1923 geschriebenen „Psalmus Hungaricus“ änderte dann die Situation. Dessen internationaler Ruhm erfolgte als Ergebnis der Zürcher Aufführung im Rahmen des IGNM-Festivals im Jahre 1926, ${ }^{22}$ nach der viele Dirigenten, darunter Toscanini, Mengelberg und Abendroth das Werk in ihr Repertoire aufnahmen. ${ }^{23}$ Die erste Aufführung des „Psalmus Hungaricus“ im Wiener Musikvereinsaal am 6. November 1927 wurde in einem Arbeiter-Sinfonie-Konzert von Anton Webern dirigiert. ${ }^{24}$

$\mathrm{Zu}$ Recht erwarteten die Dirigenten neue Orchesterwerke von Kodály. Damals hatte er aber noch keine Kompositionen dieser Art verfaßt. Nur der internationale Erfolg sowie der vermeintliche Druck der Universal-Edition bewegten ihn dazu, Werke für Orchester zu schreiben. Das erklärt, warum alle seine ersten Orchesterwerke Bearbeitungen sind. Zwischen 1927 und 1933 stellte er sechs

19 Rudolf Klein, Kodály és az Universal Edition [Kodály und die Universal-Edition], in: Ferenc Bónis (Hg.), Magyar zenetörténeti tanulmányok Kodály Zoltán emlékére [Studien zur ungarischen Musikgeschichte in Erinnerung an Zoltán Kodály], Budapest 1977, S. 136-150, hier S. 137.

20 Rudolf Réti, Gruß an Kodály, in: Anbruch, Dezember 1932 (Anm. 17), S. 189f. Nach Rétis Gruß folgt hier Aladár Tóths Artikel „Zoltán Kodály“ (S. 191-194).

21 Rudolf Klein (Anm. 19), S. 137.

22 László Eősze (Anm. 8), S. 110f.

23 János Breuer, Kodály-kalauz (Anm. 3), S. 123.

24 Über Kodálys Beziehung zu Wien siehe János Breuer, Zoltán Kodály und Wien, in: Österreichische Musikzeitschrift 27/11 (November 1972), S. 581-587. 
Orchesterwerke zusammen, drei davon waren dem Singspiel „Háry János“ entnommen: Neben der „Háry-Suite“, die ihrer Gattung nach ursprünglich aus Promotionsgründen erstellt wurde - wie Bartóks Suite aus dem „Wunderbaren Mandarin“ oder dem „Holzgeschnitzten Prinzen“ sowie Alban Bergs „Lulu-Suite“ -, hob Kodály aus dem Singspiel den Drachentanz als „Ballettmusik“ und die Ouvertüre heraus. ${ }^{25}$ Die Reihe „Marosszéker Tänze“ wurde ursprünglich als Klavierwerk konzipiert; Kodály war erst 1929 bereit, seine Komposition zu orchestrieren. Damals bearbeitete er auf die Bitte Arturo Toscaninis hin seine 1906 geschriebene Diplomarbeit, das Orchesterwerk „Sommernacht“. ${ }^{26}$ Die 1933 geschriebenen „Tänze aus Galanta“ stellten das erste selbständige Orchesterwerk Kodálys dar.

Die Universal-Edition hatte lange mit den Uraufführungsdaten manipuliert, weil der Verlag Kodálys internationalen Erfolg bedeutender erscheinen lassen wollte. Die „Háry-Suite“ wurde zum Beispiel von dem „Pau [Pablo] Casals Orchester" unter der Leitung von Antal Fleischer am 24. März 1927 in Barcelona erstaufgeführt, der Verlag propagierte jedoch die Aufführung der New Yorker Philharmoniker unter der Leitung von Willem Mengelberg als Uraufführung (15. Dezember 1927). ${ }^{27}$ Dasselbe geschah mit den von Fritz Busch und der Staatskapelle Dresden am 28. November 1930 uraufgeführten „Marosszéker Tänzen“. Die Universal Edition inserierte die Erstaufführung, als ob sie mit den New Yorker Philharmonikern unter Arturo Toscanini stattgefunden hätte. ${ }^{28}$ Hermann Scherchen meinte, er habe die Erstaufführung der Theater-Ouvertüre in Winterthur dirigiert. ${ }^{29}$

Es ist evident, daß Kodály seinen eigenen Orchesterstil erst nach dem Erfolg des "Psalmus Hungaricus" herausbilden wollte. Die Theater-Ouvertüre, die Bence Szabolcsi 1928 als "das bedeutendste symphonische Werk Kodálys" und das "größte der monumentalen Hauptwerke der neuen ungarischen Musik“ apostrophierte und in der er die „Verkörperung von Kodálys grandioser nationaler Erneuerung ${ }^{\text {c }}$ sah ${ }^{30}$ war eigentlich ein Experiment. Die experimentale Attitüde

25 Die Ballettmusik wurde aus dem Drachentanz entwickelt. Breuer, Kodály-kalauz (Anm. 3), S. 150f.

26 Siehe dazu das Vorwort der Partitur: Zoltán Kodály, Nyári este [Sommernacht], in: ders., Visszatekintés. Összegyüjtött írások, beszédek, nyilatkozatok II [Rückblick. Gesammelte Schriften, Reden, Aussagen II], hrsg. von Ferenc Bónis, Budapest 1974, S. 486.

27 Breuer, Kodály-kalauz (Anm. 3), S. 145.

28 Ebenda.

29 Ebenda, S. 153.

30 Bence Szabolcsi, A Háry János új számai (Anm. 2), S. 84. 
dürfte der Grund dafür sein, warum die meisten Rezensenten des Werkes weniger begeistert waren als Szabolcsi. Der zum Kreis von Arnold Schönberg gehörende Alexander Jemnitz schrieb in seiner Kritik:

„Ich berichte nicht gern über diese Ouvertüre [...]. Diese Ouvertüre ist tatsächlich eine schwache Komposition. [...] Das Werk, das zu ausgedehnt ist, setzt sich aus ganz und gar fremden Ideen zusammen, die aneinandergereiht sind, und obgleich die Reprise das Ganze als Sonatenform abrundet, gleicht der Satz einem Potpourri. Auch die klassizisierend strenge Wiederholung wirkt nicht überzeugend, sondern eher oberflächlich." ${ }^{31}$

Selbst Hermann Scherchen beklagte sich wegen Kodálys Ouvertüre in einem Brief an seine spätere Frau:

„Dabei ist mir auch noch das Pech gekommen, dass Kodálys neues Stück, das ich uraufführe, schlecht ist. Wenigstens ist es in keiner Weise der Háry-János-Suite selbst, zu der sie eine später hinzukomponierte Ouvertüre darstellt, ebenwertig. “32

Die Umqualifizierung des Háry-Vorspiels zur Theater-Ouvertüre war dadurch möglich, daß zwischen der Ouvertüre und dem Singspiel nur eine geringe thematische Verbindung besteht. Die Ouvertüre faßt nur die poetische Botschaft des Singspiels zusammen. Wie Jemnitz darauf hinwies, ist die Ouvertüre in Sonatenform geschrieben, nur die Themen stehen - im Gegensatz zu Jemnitzs Behauptung - in enger Beziehung zueinander (Tabelle 1). Haupt- und Seitenthema vertreten zwei verschiedene Formen desselben ungarischen, auf einer Quinte aufgebauten Themas. Das Hauptthema ist männlich-heroisch, das Seitenthema dagegen weiblich-lyrisch. Den Heroismus des Hauptthemas beweist eine von Kodály sonst nicht verwendete Vortragsanweisung: „eroico ma cantabile“.33 Das Verbunkos-Motiv der Schlußgruppe entfaltet sich aus den Skalen des Seitenthemas.

Die Ouvertüre steht keineswegs in strenger Sonatenform, wie Alexander Jemnitz meinte: Es fehlt in ihr das sogenannte „double return“, das heißt: nur das Hauptthema kehrt in der Reprise zurück, die Tonart nicht. Kodály arbeitet mit einem bestimmten Tonart-Plan: Er beginnt das Werk in a-Moll, der Grundtonalität des „Psalmus Hungaricus“. Die Thematik weist hier außerdem auf den tragischen ungarischen Ton der orchestralen Einleitung des Psalmus hin. Kodály bleibt dennoch nicht bei diesem Ton: Das lyrische Seitenthema steht in fis-Moll, was später auch die Tonart der Durchführung wird, weil die Schlußgruppe nach

31 Sándor Jemnitz: Operaház [Opernhaus.], in: Lampert (Anm. 1), S. 123f.

32 Hermann Scherchen, ...alles hörbar machen. Briefe eines Dirigenten. 1920-1939, hrsg. von Eberhardt Klemm, Berlin 1976, S. 172.

33 Zwei nach Ziffer 12 (Takt 249). 
G-Dur ausweicht. Die Reprise läßt den Modulationsvorgang genau umgekehrt erklingen: Nach dem e-Moll-Beginn des Hauptthemas ertönt das Seitenthema in des-Moll, später in cis-Moll, die Schlußgruppe steht in B-Dur. Die Schlußkadenz wird - dem Modell der Exposition entsprechend - um eine kleine Sekunde tiefer nach A-Dur verlegt. Die Tonart kehrt nicht in das tragische ungarische a-Moll des Anfangs zurück.

\begin{tabular}{|c|c|c|c|}
\hline Exposition & Durchführung & Reprise & Coda \\
\hline $\begin{array}{l}\text { 1-101 } \\
\text { Hauptsatz } \\
\text { 1-32 } \\
\text { a-Moll } \\
\text { Seitensatz } \\
33-86 \\
\text { fis-Moll } \\
\text { Schlußgruppe } \\
\text { 87-101 } \\
\text { G-Dur } \rightarrow \text { Fis-Dur }\end{array}$ & $\begin{array}{l}\text { 102-239 } \\
\text { Thema/1 } \\
\text { Takt } 114 \\
\text { Thema/2 } \\
\text { Takt } 182\end{array}$ & $\begin{array}{l}240-341 \\
\text { Hauptsatz } \\
240-272 \\
\text { Tonalität } \\
\text { unbestimmt } \\
\text { Seitensatz } \\
\text { 275-318 } \\
\text { Des-Dur, } \\
\text { cis-Moll } \\
\text { Schlußgruppe } \\
\text { 319-341 } \\
\text { B-Dur } \rightarrow \text { A-Dur }\end{array}$ & $\begin{array}{l}341-420 \\
\text { Thema/1 Takt } 341 \\
\text { A-Dur } \\
\text { Thema/2 Takt } 369 \\
\text { cis-Moll } \\
\text { Hauptsatz } \\
385-420 \\
\text { A-Dur }\end{array}$ \\
\hline
\end{tabular}

Tabelle 1: Die Form der Theater-Ouvertüre

Eine weitere Eigentümlichkeit der Kodályschen Sonatenform ist die lange Coda, die nach Beethovenschen Modellen die Durchführung zitiert. Beide Formteile sind auf der Wechselfolge von zwei Verbunkos-Themen aufgebaut. Das erste Thema ist mit einem Thema der "Tänze aus Galanta" verwandt, ${ }^{34}$ das zweite ruft Erinnerungen an Militärmusik wach. Kodály verwendet hier Schlaginstrumente, Klavier und Flöten, Piccolos. Zu einer ähnlichen Lösung findet Kodály im Finale der „Marosszéker Tänze“, in dem eine Jahrmarktszene mit Militärkapelle 
stattfindet; die Hörner spielen ein volkstümliches Kunstlied. In der Ouvertüre übernehmen die Trompeten die Rolle der Hörner. ${ }^{35}$

Kodály arbeitet hier mit einem Kunstgriff, der ihm ermöglicht, durch das Aneinanderfügen musikalischer Schichten eine Collage zustandezubringen. Er wandte dieses Verfahren auch später mit Vorliebe an; Beispiele hiefür finden wir in den „Pfau-Variationen“, im Concerto und in der Symphonie. Den Ausgangspunkt der Collage-Technik bildet selbstverständlich das kontrapunktische Denken, das vor allem in der Durchführung vorhanden ist. Die kontrapunktischen Bewegungen schließen sich hier - wie auch später im Concerto und in der Symphonie ${ }^{36}$ - zum Orgelpunkt zusammen. Die Durchführung führt zum Höhepunkt der Komposition: Der gebundene Kontrapunkt mündet in eine Flöten-Improvisation. Kodály verband mit diesem improvisatorischen Ton seit dem 1905 geschriebenen Adagio das Bild des betrübten Magyars. Überdies ist diese Flöten-Improvisation das einzige Zitat aus dem Singspiel: Die Improvisation erklingt am Ende des Liedes „Tiszán innen, Dunán túl“, was später zum dritten Satz der „János-HárySuite“ wurde. Der Verbunkos-Ton, der zum ersten Mal in der Schlußgruppe erscheint und in der Durchführung dann dominant wird, stellt später in den zwei Tanzreihen sowie im berühmten Intermezzo des Háry-Singspiels eine markante Eigentümlichkeit dar.

Deutlich sichtbar benutzt die Theater-Ouvertüre nur ungarische Themen, obwohl in ihr keine authentische Volksmusik vorhanden ist. Die punktierten Noten, die typischen Instrumentalformeln, die zu Pentatonik neigenden Melodien weisen auf einen modernen ungarischen Stil hin. Bence Szabolcsi übertrieb zwar, wenn er die geheime Botschaft der Ouvertüre mit dem Ungartum verknüpfte, er irrte sich jedoch nicht. Die in der Ouvertüre erscheinenden charakteristischen Ideen - die zentralen Begriffe des Kodályschen CEuvres, die auch seine späteren Orchesterwerke kennzeichnen - treten hier in einer ersten Formulierung auf: das Mann-Frau-Verhältnis in der Form von thematisch verwandten Haupt- und Seitenthemen, das Vaterland mit Hilfe von betont ungarischer Thematik, die Tragödie des ersten Weltkrieges in der Form von Militärmusik sowie das nationale Leid, charakterisiert durch instrumentale Improvisation, treten als Hauptgedanken in allen seinen späteren, reiferen Orchesterkompositionen auf.

35 Theater-Ouvertüre: ab Takt 18, Marosszéker Tänze: Takte 319-327.

36 Theater-Ouvertüre: Takte 132-185 - Orgelpunkt F, Takte 185-210 - Orgelpunkt B; Concerto: Takte 347-350 - Orgelpunkt G, Takte 351-361 - Orgelpunkt Fis; Symphonie, 3. Satz: Takte 411-425 - Orgelpunkt A, Takte 426-435-Orgelpunkt G. 
Zweifellos fassen die späteren Werke - wie die zwei Tanzreihen, die Pfau-Variationen und das Concerto - die Kodályschen Gedanken wirksamer zusammen als die Ouvertüre, die im Vergleich zu ihnen nur ein Experiment ist. Noch dazu war die Wiener Uraufführung verspätet, da die reifen Werke von 1932 bereits bekannt und erfolgreich geworden waren. Das kann der Grund dafür sein, warum das Werk in Konzerten fast nie ertönt und auch in den János-HáryAufführungen weggelassen wird. Trotzdem kann die Theater-Ouvertüre als ein Schlüsselwerk von Kodálys CEuvre angesehen werden, in der Kodály zum ersten $\mathrm{Mal}$ versuchte, einige Gedanken über sein Leben und sein Land in der Sprache des Orchesters zu erzählen.

Abschließend sei die im Abendprogramm der Uraufführung (S. 174) abgedruckte, leider ungezeichnete Charakterisierung des Werkes mitgeteilt:

\section{Zoltán Kodály: Singspiel=Ouverture}

Das Märchenspiel: „Háry János“ schildert die Abenteuer dieses ungarischen Münchhausen auf seiner Reise von Groß=Abony bis zur Wiener Hofburg. Dieses Singspiel, welches durch ein kurzes Stück mit der Überschrift: „Das Märchen beginnt“ eingeleitet wird, fand seine erfolgreiche Erstaufführung in Köln am 26. September 1931. Nunmehr hat Kodály in allerletzter Zeit eine Ouverture gleichen Namens geschrieben, welche wohl, wenn man nach ihrer breiteren Ausführung Schlüsse ziehen darf, nicht als Einleitung zum Bühnenwerk gedacht ist, sondern als selbständige Konzertouverture angesehen werden muß, die ihr thematisches Material dem größeren Werke entlehnt.

Unter flimmernder Tremolobegleitung der hohen Streicher setzen im dritten Takte des Allegro molto Fagotte, Hörner, Celli und Bässe mit einem rassigen, marcatissimo vorgetragenen und langatmigen, synkopierten Thema ein, das die Ouverture beherrscht. Andere Instrumente gesellen sich hinzu. Absteigende Figuren führen ins Pianissimo, aus welchem sich wiederholt das Thema solistisch, hauptsächlich in den Blasinstrumenten, hervorhebt. Plötzlich eine Halt gebietende Generalpause. Dieser folgen, von einer zweiten solchen abgeschlossen, vier Takte, die das zweite Thema der Ouverture bringen. Es entstammt dem 21. Stück des Bühnenwerkes, dem Liede: „Mich ärgert der Raufbold so“. Man könnte fast von einer fugenartigen Durchführung dieses zweiten Themas sprechen, da sich nacheinander viele Stimmen an seiner Verarbeitung beteiligen. Auch die Dazwischenkunft eines markigen, vom zweiten Takte an punktierten Motives, welches ebenfalls dem oben erwähnten Liede entnommen ist, unterbricht nur zeitweise diese Durchführung.; bald erklingt es wieder, dieses Mal in Engführung, bis es dem Wiedereintritte des Hauptthemas weichen muß. Hiemit beginnt die stark modifizierte Reprise; von einer solchen kann man insoferne sprechen, als von hier ab kein neues Thema mehr auftritt, sondern nur bereits Bekanntes verarbeitet wird. Instrumentation, Harmonik und Koloristik sind aber ganz unabhängig vom ersten Teile geschaffen.

Gegen Schluß des Werkes läßt der Komponist das zweite Thema als Kontrapunkt zum ersten, synkopierten, treten und vereinigt so die beiden wichtigsten, am Aufbau der Ouverture beteiligten Faktoren zu intensiver, wirksamer Schlußsteigerung. 